\title{
Substances Derived from 4-Ethyl Octanoic Acid Account for Primer Pheromone Activity for the "Male Effect" in Goats
}

\author{
Eri IWATA ${ }^{1)}$, Takefumi KIKUSUI ${ }^{1)}$, Yukari TAKEUCHI ${ }^{1)}$ and Yuji MORI ${ }^{1)}$ \\ ${ }^{1)}$ Laboratory of Veterinary Ethology, The University of Tokyo, 1-1-1 Yayoi, Bunkyo-ku, Tokyo 113-8657, Japan
}

(Received 8 February 2003/Accepted 15 May 2003)

ABSTRACT. A major constituent of the characteristic "goaty odor" 4-ethyl octanoic acid (4EOA) was previously shown to have no primer pheromone activity. This was also confirmed by our own bioassay system utilizing the recording technique of neural activity of the hypothalamic gonadotropin-releasing hormone pulse generator in goats. However, when the synthetic 4EOA solution was kept at room temperature for several months, primer pheromone activity appeared in the same solution. Headspace gas chromatography/mass spectrometry analysis revealed that there were several newly formed substances in addition to 4EOA samples with primer pheromone activity. These results suggest that 4EOA derived substance(s) but not $4 \mathrm{EOA}$ itself is(are) primer pheromone in goats.

KEY WORDS: 4-ethyl octanoic acid, goat, pheromone.

J. Vet. Med.Sci. 65(9): 1019-1021, 2003

Pheromones are defined as chemical signals among conspecifics and its priming effects are to modulate reproductive physiology [13]. In small ruminant such as sheep and goats, primer pheromones produced by the male have been known to stimulate the reproductive neuroendocrine system of anestrous females, which is known as the "male effect", leading to out-of-seasonal ovulation $[1,7,9]$. The pheromone substance(s) responsible for this phenomenon have been found to exist in hair, skin, and their extracts with organic solvents $[1,3,7]$ of male goats. In previous studies, 4-ethyl octanoic acid (4EOA) and some related substances were found to be the main constituents of the characteristic "goaty odor" of mature male goats [10-12]. It was reported that synthetic 4EOA possessed a "releaser" pheromone activity, which induced specific behavior of recipients, and female goats showed some interest in the odor [10]. However, it was subsequently revealed that 4EOA does not have any "primer" pheromone activity, based on the finding that it could not stimulate the pulsatile secretion of luteinizing hormone $(\mathrm{LH})$, which is necessary for initiating the preovulatory neuroendocrine events [2]. The lack of primer pheromone activity in synthetic 4EOA was also confirmed by our own bioassay system, which utilized electrophysiological monitoring of hypothalamic neural activity in goats [4].

However, we recently found, rather unexpectedly, that the synthetic 4EOA solution that had been used as the negative control in each bioassay turned into positive in its pheromone activity following several months of storage at room temperature. To our knowledge, this kind of drastic change in biological activities has never been reported, and it was suggested that it was due to the formation of some impurities derived from 4EOA. In the present study, we conducted a chemical analysis using headspace gas chromatography/ mass spectrometry (HS-GC/MS) in combination with a neurophysiological bioassay to identify the pheromone candidate molecules that had formed in the 4EOA solution during the course of storage.
Synthetic 4EOA was obtained from Takasago International Corporation (Tokyo, Japan) on September 1999. At beginning, the synthetic 4EOA showed no primer pheromone activity until 125 days after acquisition. Then it was stored at room temperature, and the pheromone activity appeared suddenly by 206 days after the acquisition. All the bioassays carried out thereafter revealed that the substance contained robust pheromone activity. So the mass chromatographic profiles before and after the appearance of pheromone activity were compared.

HS-GC/MS analysis was performed using the Agilent HP6890 (Agilent, Palo Alto, CA, U.S.A.) with a fused silica capillary column $(30 \mathrm{~m} \times 0.25 \mathrm{~mm} \times 0.25 \mu \mathrm{m}$, HP-INNOWAX, Agilent, Palo Alto) equipped with the headspace sampler Agilent 7694 (Agilent, Palo Alto), and helium was used as the carrier gas. A glass vial containing $10 \mu \mathrm{l}$ of 4EOA was heated at $80^{\circ} \mathrm{C}$ for $20 \mathrm{~min}$, and $1 \mu \mathrm{l}$ of the headspace gas of the vial was injected into the GC at split mode $(1: 10)$. The temperature of the column oven was maintained at $40^{\circ} \mathrm{C}$ for $1 \mathrm{~min}$, then increased at $4^{\circ} \mathrm{C} / \mathrm{min}$ to $160^{\circ} \mathrm{C}$, then at $7^{\circ} \mathrm{C} / \mathrm{min}$ to a final temperature of $250^{\circ} \mathrm{C}$, at which it was maintained for $8 \mathrm{~min}$. Electron impact ionization mass spectra were recorded in a full scan mode by the mass spectrometer Agilent HP5973 (Agilent, Palo Alto) with a scan range $\mathrm{m} / \mathrm{z} 35-400$. Based on the mass spectra, the candidate molecules were identified by a computer MS library search. In addition, the primer pheromone activity for each sample was assessed by neurophysiological bioassay that involved monitoring the hypothalamic gonadotropin-releasing hormone $(\mathrm{GnRH})$ pulse generator activity as described elsewhere [4-6]. In brief, the gauze containing $10 \mu \mathrm{l}$ of 4EOA was placed 2 to $3 \mathrm{~cm}$ in front of ovariectomized female goat, from which clear multiple unit activity (MUA) volleys had been consistently recorded [8]. When a following MUA volley appeared within 3 min of the sample application, the sample was assessed to be positive $[5,6]$.

Figure 1 shows total ion chromatograms (TIC) of the 


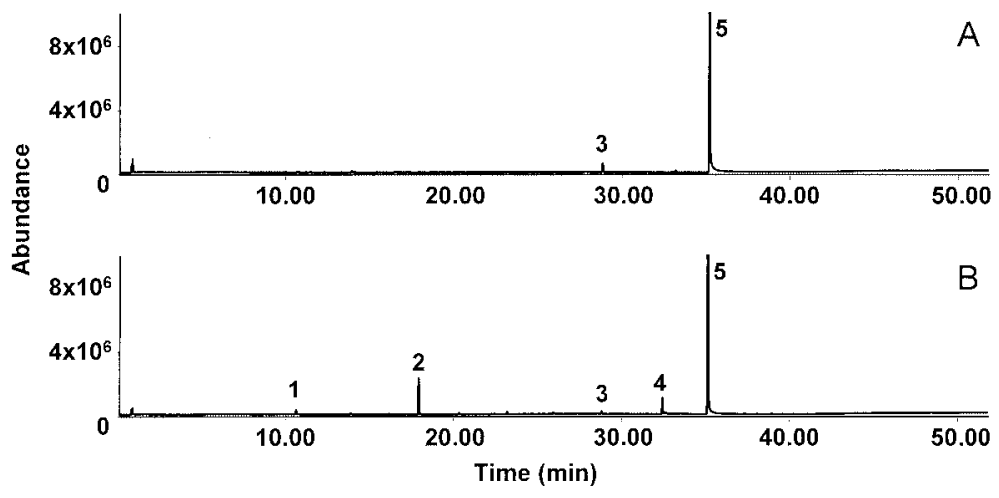

Fig. 1. Comparison of HS-GC/MS profiles of the synthetic 4EOA solution before and after the appearance of pheromone activity. (A) TIC of the 4EOA when the pheromone activity was negative by the bioassay (73 days after acquisition; November, 30, 1999). (B) TIC of the 4EOA after several months storage at room temperature, by which time the pheromone activity turned into positive ( 300 days after acquisition; July, 15, 2000). Identities of numbered peaks are listed in Table 1.

Table 1. Detected impurities in the synthetic 4EOA, in which the pheromone activity appeared

\begin{tabular}{cccl}
\hline Peak \# & $\mathrm{RT}^{\mathrm{a})}(\mathrm{min})$ & Ratio $\%$ & \multicolumn{1}{c}{ Substance } \\
\hline 1 & 10.655 & 2.63 & Unidentified \\
2 & 17.968 & 19.76 & 4-ethyl octanoic acid, methyl ester \\
3 & 28.822 & 1.78 & 2,6-di-t-buthyl-4-methylphenol (BHT) \\
4 & 32.462 & 9.02 & Octanoic acid \\
5 & 35.174 & 100.00 & 4-ethyl octanoic acid (4EOA) \\
\hline
\end{tabular}

a) Retention Time.

synthetic 4EOA solution before (73 days after acquisition; November, 30, 1999) and after (300 days after acquisition; July, 15, 2000) the appearance of the primer pheromone activity. Three peaks, which were not present initially, when the synthetic 4EOA solution had no pheromone activity, were found to emerge after several months storage. The most conspicuous peak of these was identified to be the methyl ester of 4EOA (Peak \#2, 4EOAM). The other detected peak was identified as octanoic acid (Peak \#4), and a third one was unidentified (Peak \#1), as shown in Table 1. The rest of the peaks detected were identified as silicone based substances. All 4EOA samples that turned positive in pheromone activity had similar HS-GC/MS profiles as shown on Fig. 1 (B), though only one analysis was done on negative samples.

These changes in the HS-GC/MS profiles were supposed to be related to the appearance of the primer pheromone activity in the synthetic 4EOA solution during storage at room temperature. Although the unidentified peak remains, these substances derived from 4EOA appear to contain the pheromone candidate(s) that stimulates the hypothalamic function in recipient females. From the results of present study, it is suggested that 4EOA may play an important role as a precursor of the primer pheromone(s), although 4EOA itself was found in previous study not to have any pheromone activity [2]. Therefore, we would now like to propose a working-hypothesis that the certain substance(s) that is derived from male goat specific fatty acid 4EOA is a pheromone molecule(s). To test this hypothesis in future studies, verification of whether these candidate substances are actually present in the biological materials (e.g., goat hair), and/ or synthesis of these candidate substances and assessment of their primer pheromone activity could be undertaken.

ACKNOWLEDGEMENTS. This study was supported by "Research for the Future" Program, The Japan Society for the Promotion of Science (JSPS-RFTF 97L00904), Grantsin-aid, for Scientific research from the Ministry of Education, Science, Sports, and Culture (13306022), and from CREST of the Japan Science and Technology Corporation.

\section{REFERENCES}

1. Chemineau, P. 1987. Livest. Prod. Sci. 17: 135-147.

2. Claus, R., Over, R. and Denhard, M. 1990. Anim. Reprod. Sci. 22: $27-38$.

3. Cohen-Tannoudji, J., Einhorn, J. and Signoret, J.P. 1994. Physiol. Behav. 56: 955-961.

4. Hamada, T., Nakajima, M., Takeuchi, Y. and Mori, Y. 1996. Neuroendocrinology 64: 313-319.

5. Iwata, E., Wakabayashi, Y., Kakuma, Y., Kikusui, T., Takeuchi, Y. and Mori, Y. 2000. Biol. Reprod. 62: 806-810.

6. Iwata, E., Wakabayashi, Y., Matsuse, S., Kikusui, T., Takeuchi, Y. and Mori, Y. 2001. J. Vet. Med. Sci. 63: 347-348.

7. Knight, T.W. and Lynch, P.R. 1980. Anim. Reprod. Sci. 3: 
133-136.

8. Nishihara, M., Mori, Y., Yoo, M. J., and Takahashi, M. 1994. pp. 114-126. In: Methods in Neuroscience, vol. 20 (Levine, J. E. ed.). Academic Press, San Diego.

9. Ott, R., Nelson, D. and Hixon, J. 1980. Theriogenology 13: 183-190.

10. Sasada, H., Sugiyama, T., Yamashita, K. and Masaki, J. 1983. Jpn. J. Zootech. Sci. 54: 401-408.
11. Sugiyama, T., Sasada, H., Masaki, J. and Yamashita, K. 1988. Agric. Biol. Chem. 45: 2655-2658.

12. Sugiyama, T., Sasada, H., Masaki, J. and Yamashita, K. 1990. pp. 53-62. In: Pheromones and Reproduction (Sagara, Y. and Seto, K. eds.), Parthenon Publishing Group, New Jersey.

13. Wilson, E. and Bossert, W. 1963. Rec. Prog. Horm. Res. 19: 673-710. 